\title{
Targeting of BMI-1 with PTC-209 shows potent anti-myeloma activity and impairs the tumour microenvironment
}

\author{
Arnold Bolomsky ${ }^{1}$, Karin Schlangen², Wolfgang Schreiner ${ }^{2}$, Niklas Zojer ${ }^{1}$ and Heinz Ludwig ${ }^{{ }^{*}}$
}

\begin{abstract}
Background: The polycomb complex protein BMI-1 (BMI-1) is a putative oncogene reported to be overexpressed in multiple myeloma (MM). Silencing of BMI-1 was shown to impair the growth and survival of MM cells. However, therapeutic agents specifically targeting BMI-1 were not available so far. Here, we investigated PTC-209, a novel small molecule inhibitor of BMI-1, for its activity in MM.
\end{abstract}

Methods: BMI-1 expression was analysed in human MM cell lines and primary MM cells by using publically available gene expression profiling (GEP) data. The anti-MM activity of PTC-209 was investigated by viability testing, cell cycle analysis, annexin V and 7-AAD staining, quantification of cleaved poly(ADP-ribose) polymerase (PARP), JC-1 as well as colony formation assays. Deregulation of central myeloma growth and survival genes was studied by quantitative PCR and flow cytometry, respectively. In addition, the impact of PTC-209 on in vitro osteoclast, osteoblast and tube formation was analysed.

Results: We confirmed overexpression of BMI-1 in MM patients by using publically available GEP datasets. Of note, BMI-1 expression was further increased at relapse which translated into significantly shorter overall survival in relapsed/refractory patients treated with bortezomib or dexamethasone.

Treatment with PTC-209 significantly decreased viable cell numbers in human MM cell lines, induced a G1 cell cycle arrest, promoted apoptosis and demonstrated synergistic activity with pomalidomide and carfilzomib. The anti-MM activity of PTC-209 was accompanied by a significant decrease of cyclin D1 (CCND1) and v-myc avian myelocytomatosis viral oncogene homolog (MYC) expression as well as upregulation of cyclin-dependent kinase inhibitor $1 \mathrm{~A}(C D K N 1 A)$ and cyclin-dependent kinase inhibitor 1B (CDKN1B). We also observed upregulation of NOXA (up to $3.6 \pm 1.2$-fold induction, $P=0.009)$ and subsequent downregulation of myeloid cell leukemia $1(\mathrm{MCL}-1)$ protein levels, which likely mediates the apoptotic effects of PTC-209. Importantly, the anti-MM activity was upheld in the presence of stromal support or myeloma growth factors insulin-like growth factor 1 (IGF-1) and interleukin 6 $(\mathrm{IL}-6)$.

In the MM microenvironment, PTC-209 impaired tube formation, impaired osteoclast development and decreased osteoblast formation in a dose-dependent manner $(P<0.01$ at $1 \mu \mathrm{M}$, respectively). The latter might be attributed to an induction of DKK1 and was reversed by concurrent anti-DKK1 antibody treatment.

Conclusions: We confirmed overexpression of BMI-1 in MM highlighting its role as an attractive drug target and reveal therapeutic targeting of BMI-1 by PTC-209 as a promising novel therapeutic intervention for MM.

Keywords: Multiple myeloma, BMI-1, PTC-209, Microenvironment

\footnotetext{
* Correspondence: heinz.ludwig@wienkav.at

${ }^{1}$ Wilhelminen Cancer Research Institute, Department of Medicine I,

Wilhelminenspital, Montleartstraße 37, 1160 Vienna, Austria

Full list of author information is available at the end of the article
} 


\section{Background}

Multiple myeloma (MM) arises from the clonal growth of malignant plasma cells in the bone marrow (BM) [1]. Treatment options for MM are continuously improving, leading to significantly increased response rates as well as prolonged survival $[1,2]$. Despite this progress, myeloma remains a difficult-to-treat disease with the vast majority of patients eventually relapsing. Therefore, the identification of novel drug targets and introduction of additional therapeutic agents are urgently needed to improve the efficacy of existing therapies, to overcome drug resistance and to unravel additional drugable key players in the pathophysiology of MM.

The polycomb complex protein BMI-1 (BMI-1) constitutes a pleiotropic factor with implications in the regulation of the cell cycle, DNA damage response, apoptosis, senescence as well as stem cell self-renewal and differentiation [3]. BMI-1 was originally discovered as a cooperation factor for $\mathrm{v}$-myc avian myelocytomatosis viral oncogene homolog (MYC) in lymphomagenesis and constitutes a central component of the polycomb repressive complex 1 (PRC1), an epigenetic repressor complex which acts through histone H2A monoubiquitination at lysine 119 [4-8]. Overexpression of BMI-1 was frequently observed in diverse human malignancies and associated with tumour initiation and propagation, disease progression and poor prognosis [9-13]. Moreover, BMI-1 was shown to mediate the growth and survival of cancer stem cells in several solid and haematological malignancies [14-17].

BMI-1 represents an attractive drug target in myeloma as well. Upregulation of BMI-1 has been reported previously in MM, and silencing of BMI-1 by small hairpin (sh) RNA significantly impaired the proliferation and colony formation of myeloma cells [18, 19]. Furthermore, silencing of BMI-1 induced apoptosis in vitro and in vivo through upregulation of BCL2-like 11 (Bim) expression in MM cells [19]. More recent results demonstrated that shRNA-mediated silencing of BMI-1 also sensitizes myeloma cells to bortezomib, which was attributed to increased expression of p21 and BCL2associated X protein (Bax) [20]. However, despite the identification of BMI- 1 as an attractive drug target in myeloma and various other malignancies, inhibitors specifically targeting BMI-1 have not been available so far.

Kreso et al. recently reported targeting of colorectal carcinoma with PTC-209, a novel small molecule inhibitor of BMI-1 [21]. Treatment of colorectal cancer cells reduced BMI-1 protein levels and significantly impaired tumour growth in vitro and in vivo. Importantly, PTC-209 also targeted cancer-initiating cells [21]. Treatment of chronic and acute myeloid leukemia cells with PTC-209 was likewise shown to impair tumour growth and survival $[22,23]$. We therefore aimed to investigate the pre-clinical activity of PTC-209 in myeloma and to explore the impact of BMI-1 inhibition on the tumour microenvironment.

\section{Results}

BMI-1 is overexpressed in multiple myeloma and associated with survival

We confirmed overexpression of $B M I-1$ in $\mathrm{CD} 138^{+}$purified cells of monoclonal gammopathy of undetermined significance (MGUS), smouldering multiple myeloma (SMM), newly diagnosed and relapsed MM patients compared to healthy controls in publically available gene expression profiling (GEP) datasets. As expected, BMI-1 expression was significantly $(P<0.0001)$ elevated in $M M$ patients (newly diagnosed and relapsed) compared to healthy donor bone marrow plasma cells (BMPCs). Of note, BMI-1 expression was already increased in CD138 ${ }^{+}$ cells of MGUS and SMM patients. We also examined BMI-1 expression levels in total therapy 2 (TT2)- and TT3-treated patients at baseline and relapse. This analysis indeed demonstrated a significant increase of BMI1 expression at relapse in patients treated within the TT3 protocol $(P=0.016)$ (Fig. 1a). In line with this observation, relapsed and/or refractory patients with low BMI-1 expression treated with bortezomib or dexamethasone displayed a superior prognosis compared to patients with high BMI-1 expression (median overall survival [OS] 22.2 vs 13.7 months, $P=0.003$ ) (Fig. 1b). These results confirmed overexpression of $B M I-1$ in all stages of MM progression and therefore highlight its putative role as an attractive drug target in myeloma.

\section{PTC-209 impairs myeloma cell growth and survival}

In line with the GEP analysis and previous reports, BMI-1 gene and protein expression was observed in eight of eight human myeloma cell lines (HMCLs) tested (not shown). Treatment with PTC-209 led to downregulation of BMI-1 protein levels (Fig. 2a) and significantly impaired viability of all HMCLs analysed with IC50 values $<2 \mu \mathrm{M}$ in six of eight HMCLs (range 0.21-5.68 $\mu \mathrm{M}$ ) (Fig. 2b). No significant association was observed between IC50 values and BMI-1 mRNA $(R=-0.32, P=0.44)$ or protein expression ( $R=-0.43, P=0.29$ ). In contrast to HMCLs, IC50 values were not reached in healthy donor peripheral blood mononuclear cells (PBMCs) (range 15-629 $\mu \mathrm{M}$ ) and bone marrow stromal cells (BMSCs) TERT $^{+}$cells (IC50: $54 \mu \mathrm{M}$ ) (Fig. 2c). Analysis of gene expression after short-term incubation (5 h) with PTC-209 demonstrated deregulation of cell cycle-associated genes. We observed significant downregulation of cyclin D1 (CCND1) (up to $0.67 \pm 0.04$ fold reduction, $P<0.001$ ) and $M Y C$ (up to $0.50 \pm 0.07$-fold reduction, $P<0.001$ ) as well as upregulation of the cell cycle inhibitory genes cyclin-dependent kinase inhibitor 1A (CDKN1A) (up to $3.4 \pm 0.4$-fold increase, $P<0.001$ ) 


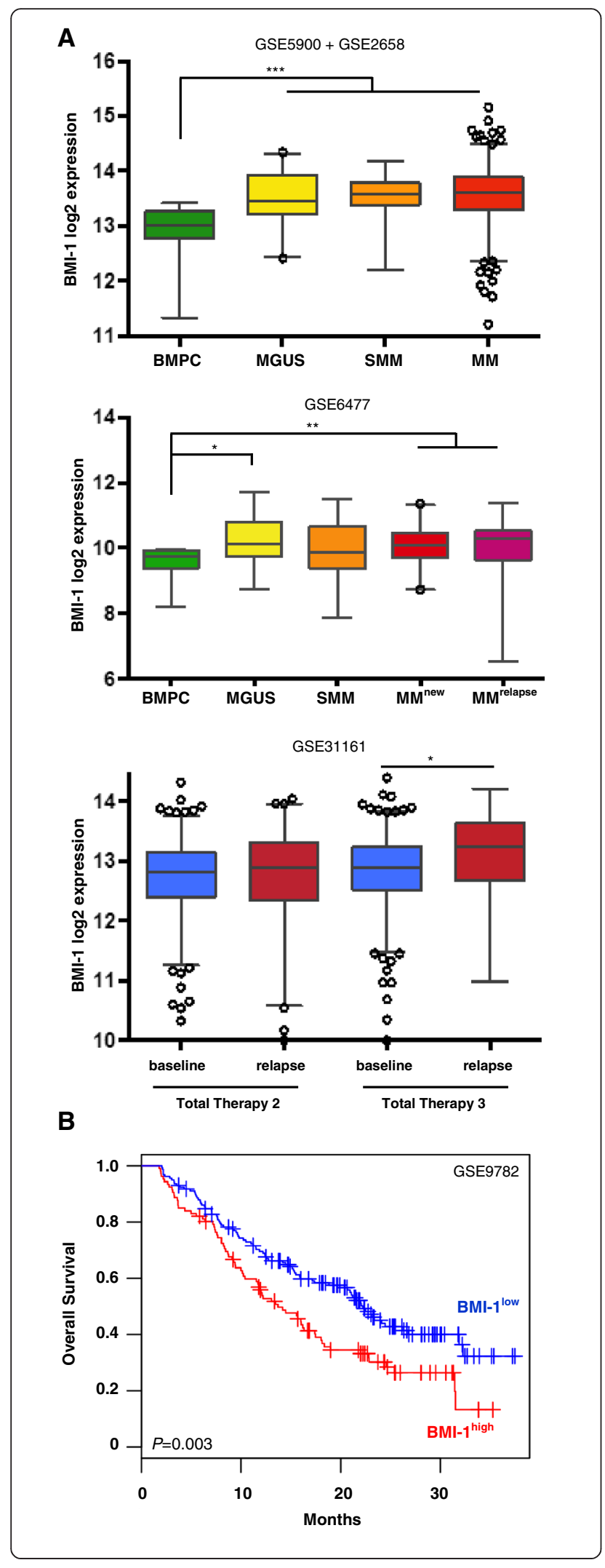

Fig. $1 \mathrm{BMI}-1$ is overexpressed in multiple myeloma and associated with outcome. a BMI- 1 expression analysis of CD138 ${ }^{+}$purified cells in publically available gene expression datasets displayed significant overexpression in MGUS, SMM and MM patients compared to healthy donor plasma cells. In addition, BMI-1 expression was increased at relapse $(n=29)$ compared to baseline $(n=433)$ in patients treated within TT3, but not in those of TT2 ( $n=172$ and $n=346$, respectively). Boxplots represent median BMI-1 expression (line) and 2.5-97.5 percentile (bars). ${ }^{* *} P<0.001$, ${ }^{*} P<0.01$ and ${ }^{*} P<0.05$. b High $B M l-1$ expression was associated with poor outcome in relapsed and/or refractory patients treated with bortezomib or dexamethasone (GSE9782) $(n=264)$. Samples were divided into two groups based on the maximally selected rank statistics cutoff

and cyclin-dependent kinase inhibitor 1B (CDKN1B) (up to $2.1 \pm 0.6$-fold increase, $P=0.03$ ) (Fig. $2 \mathrm{~d}$ ). This translated into a significant accumulation of cells in the G1 phase and concurrent reduction of cells in the S and G2M phase of the cell cycle after $24 \mathrm{~h}$ of treatment with PTC209 at $1 \mu \mathrm{M}$ (Fig. 2e).

In addition to the anti-proliferative effects, PTC-209 significantly impaired the number and size of colonies formed by myeloma cells in a colony formation assay (OPM-2: $215 \pm 50$ vs $105 \pm 12$ colonies with PTC-209 at $1 \mu \mathrm{M}, P=0.005$; KMS-12-BM: $59 \pm 12$ vs $17 \pm 3, P<$ 0.001 ) and induced apoptosis in all HMCLs analysed (Fig. 3a, b). The latter was further confirmed by the presence of increased poly(ADP-ribose) polymerase (PARP) cleavage and JC-1 assay, which indicated depolarization of the mitochondrial membrane after $24 \mathrm{~h}$ treatment with PTC-209 (Fig. 3c, d). Of note, viability $96 \mathrm{~h}$ post treatment with PTC-209 at $1 \mu \mathrm{M}$ significantly correlated with the number of apoptotic cells at $72 \mathrm{~h}$ post treatment $(R=-0.78, P=0.04)$, but not with changes in the cell cycle profile. This suggests that induction of apoptosis is the main mechanism responsible for the reduction of viable cells upon PTC-209 treatment. We therefore assessed the regulation of mitochondrial genes associated with apoptosis and detected significant induction of NOXA expression in the presence of PTC-209 (up to $3.6 \pm 1.2$-fold increase, $P=$ 0.009) (Fig. 3e). In contrast, no impact of PTC-209 was observed on Bim and Bax expression levels (data not shown). In line with the proposed functions of NOXA, we observed downregulation of myeloid cell leukemia 1 (MCL-1) protein levels (Fig. 3f), suggesting that induction of apoptosis by PTC-209 is related to NOXAmediated inhibition of MCL-1.

\section{PTC-209 impairs the activity of stromal support for myeloma cells and shows synergistic activity with pomalidomide and carfilzomib}

To assess whether PTC-209 overcomes stromal-mediated drug resistance, we tested the activity of PTC-209 in the presence of insulin-like growth factor 1 (IGF-1) and 


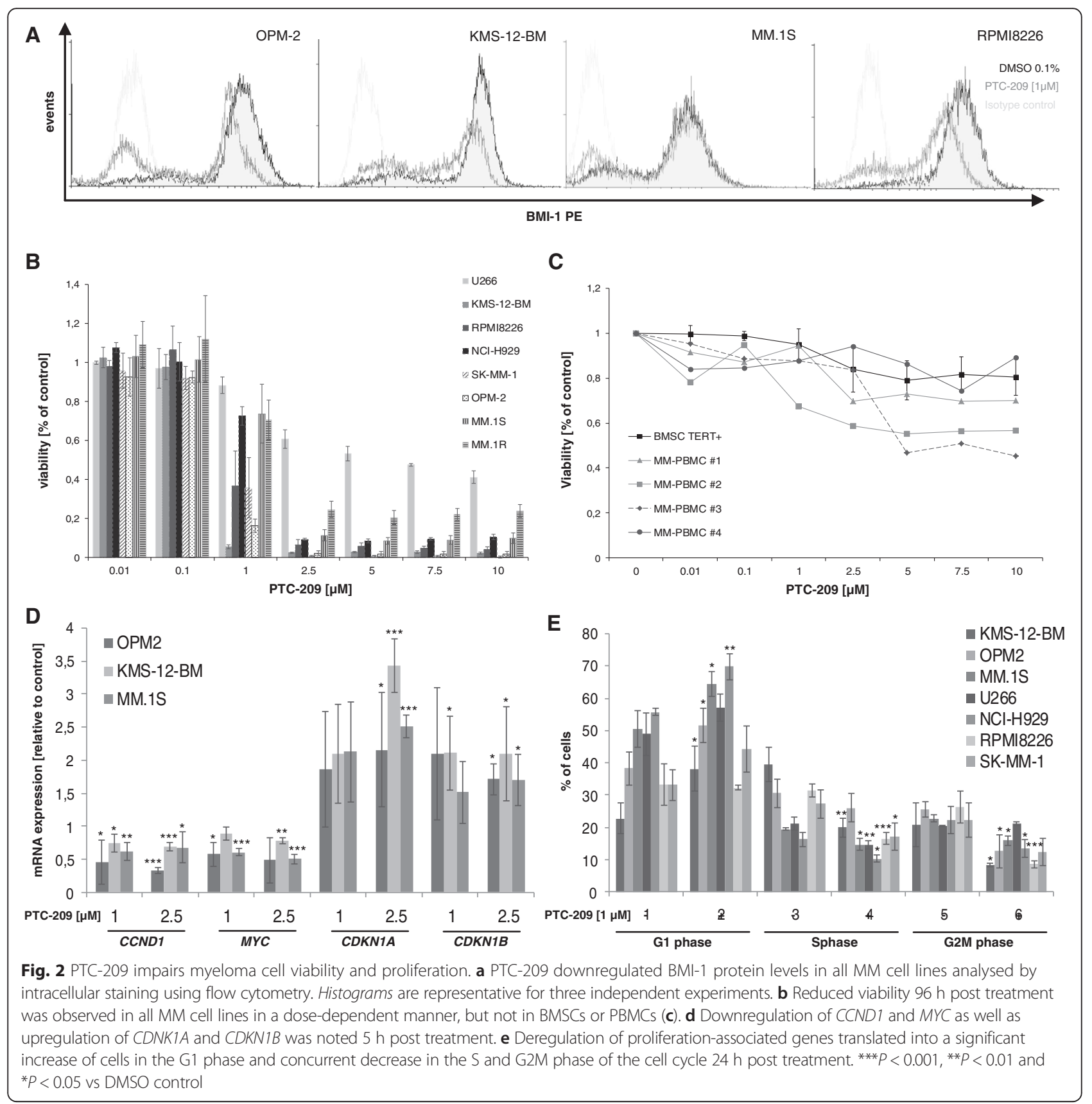

interleukin 6 (IL-6). Importantly, PTC-209 was found to impair the growth- and survival-propagating effects of both soluble factors in a dose-dependent manner in the non-autonomously surviving cell lines KMS-12-BM and MM.1S. In the autonomously surviving cell line OPM-2 (proliferate in serum-free Syn-H medium), IGF-1 and IL-6 did not show any additional effect but likewise did not rescue OPM-2 cells from the anti-MM activity of PTC-209 (Fig. 4a). When KMS-12-BM and U266 cells were cocultured with human BMSCs, PTC-209 significantly increased the rate of apoptotic cells (KMS-12-BM: 5.4 vs $36.1 \%$ apoptotic cells with PTC-209 at $1 \mu \mathrm{M}, P=0.004$;
U266: 8.9 vs $16.0 \%, P=0.05)$. Moreover, PTC-209 enhanced the anti-MM activity of pomalidomide and carfilzomib in the presence of BMSCs; although, we have to note that there was only a marginal effect in the partial resistant HMCL U266 (Fig. 4b). To verify the synergistic activity of these agents, six HMCLs were incubated with PTC-209 and either pomalidomide or carfilzomib at varying concentrations. PTC-209 displayed synergistic and/or additive drug activity in combination with carfilzomib in all HMCLs analysed, and in five of six HMCLs in combination with pomalidomide. Importantly, synergistic activity with carfilzomib and pomalidomide was also observed in 


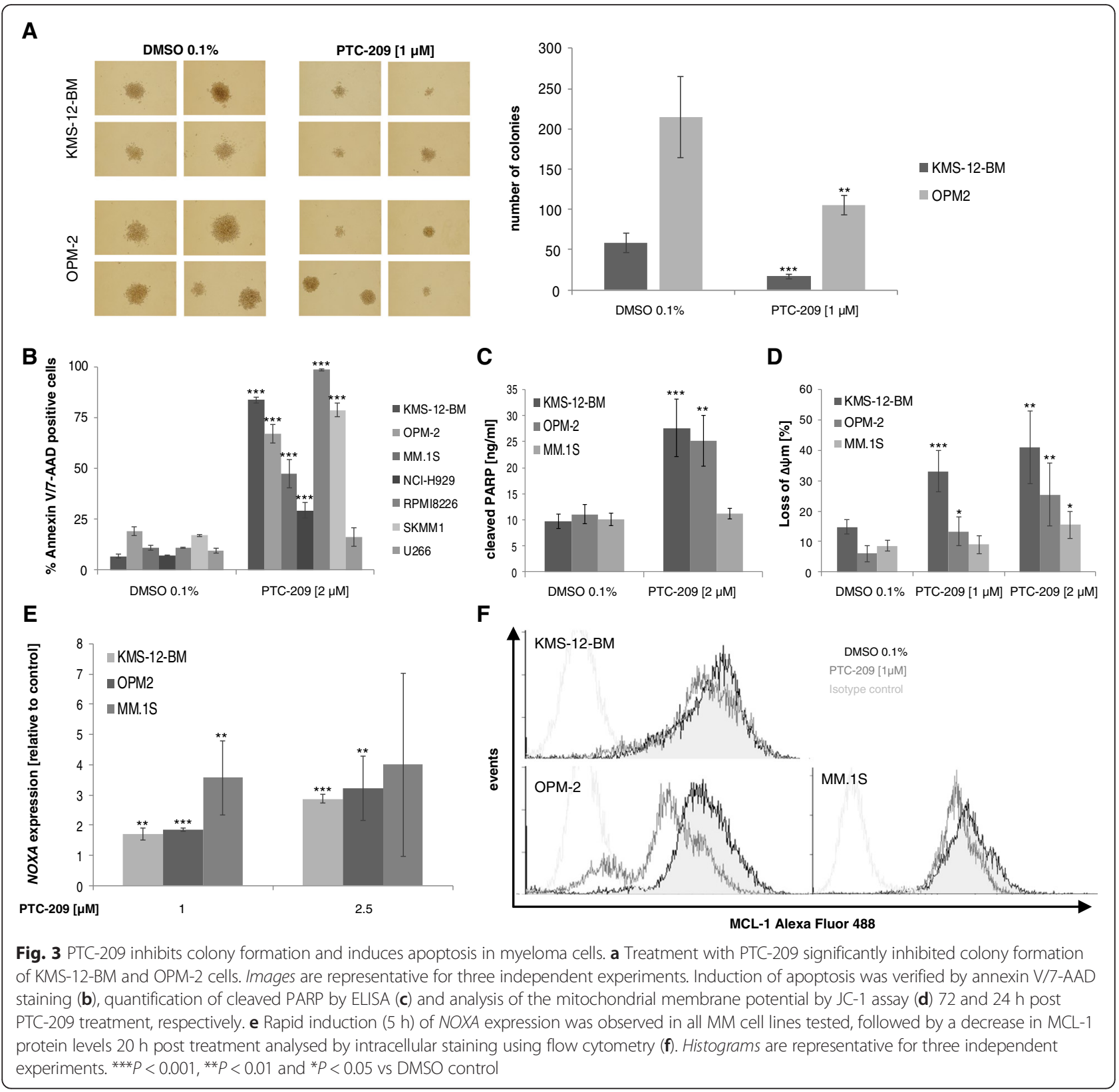

the PTC-209 partly resistant HMCL U266 (Fig. 4c). Similar results were obtained when PTC-209 was combined with dexamethasone (Additional file 1: Figure S1).

\section{PTC-209 targets the myeloma microenvironment}

As PTC-209 was shown to impair stromal-mediated drug resistance, we were interested whether it impacts the function of other cells in the myeloma microenvironment as well. Enhanced formation of osteoclasts and angiogenesis is a major hallmark of myeloma. We therefore analysed the activity of PTC-209 on these cell types. In vitro osteoclast formation of healthy donor PBMCs was significantly impaired, with no signs of tartrateresistant acid phosphatase (TRAP)-positive osteoclasts when PTC-209 was used at $1 \mu \mathrm{M}$ (Fig. 5a). This was further confirmed by decreased expression of cathepsin $\mathrm{K}$ and TRAP $(0.88 \pm 0.17$ and $0.78 \pm 0.01$-fold downregulation with $1 \mu \mathrm{M}$ PTC-209; $P<0.01$, respectively) at day 14 of osteoclast formation (Fig. 5b). Similarly, PTC-209 was found to impair in vitro tube formation in a dosedependent manner. Treatment with PTC-209 at $1 \mu \mathrm{M}$ significantly decreased the total length $(P=0.005)$, the branching interval $(P=0.002)$ as well as the number of junctions and master segments $(P=0.02$ and $P=0.01$, 

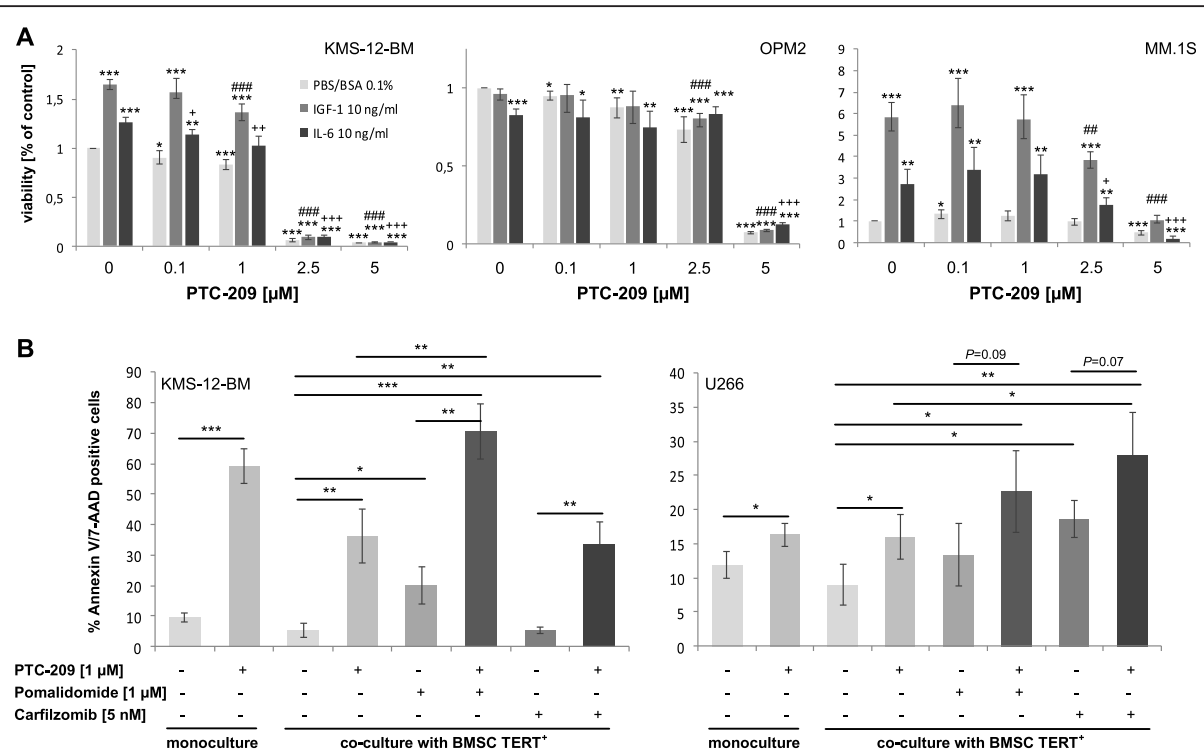

C

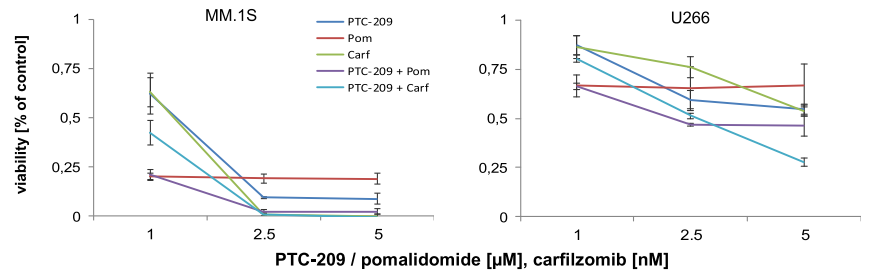

\begin{tabular}{|c|c|c|c|c|c|}
\hline & \multirow{2}{*}{$\begin{array}{l}\text { PTC-209 } \\
{[\mu \mathrm{M}]}\end{array}$} & \multirow{2}{*}{$\begin{array}{c}\text { Pomalidomide } \\
{[\mu \mathrm{M}]}\end{array}$} & \multirow{2}{*}{$\begin{array}{c}\text { Carfilzomib } \\
{[\mathrm{nM}]}\end{array}$} & \multicolumn{2}{|c|}{ Combination Index } \\
\hline & & & & PTC-209 + Pom & PTC-209 + Carf \\
\hline \multirow{3}{*}{ KMS-12-BM } & 1 & 1 & 1 & 0.36 & 0.35 \\
\hline & 2.5 & 2.5 & 2.5 & 0.60 & 0.34 \\
\hline & 5 & 5 & 5 & 1.26 & 0.81 \\
\hline \multirow{3}{*}{ OPM-2 } & 1 & 1 & 1 & 0.49 & 1.10 \\
\hline & 2.5 & 2.5 & 2.5 & 0.30 & 0.73 \\
\hline & 5 & 5 & 5 & 0.56 & 0.40 \\
\hline \multirow{3}{*}{ MM.1S } & 1 & 1 & 1 & 1.03 & 1.96 \\
\hline & 2.5 & 2.5 & 2.5 & 0.15 & 0.66 \\
\hline & 5 & 5 & 5 & 0.30 & 0.61 \\
\hline \multirow{3}{*}{$\mathrm{NCl}-\mathrm{H} 929$} & 1 & 1 & 1 & 0.47 & 0.98 \\
\hline & 2.5 & 2.5 & 2.5 & 0.30 & 0.74 \\
\hline & 5 & 5 & 5 & 0.67 & 0.54 \\
\hline \multirow[t]{3}{*}{ SK-MM-1 } & 1 & 1 & 1 & $>100$ & 0.90 \\
\hline & 2.5 & 2.5 & 2.5 & $>100$ & 0.63 \\
\hline & 5 & 5 & 5 & $>100$ & 0.94 \\
\hline \multirow[t]{3}{*}{ U266 } & 1 & 1 & 1 & 0.33 & 1.73 \\
\hline & 2.5 & 2.5 & 2.5 & 0.35 & 0.99 \\
\hline & 5 & 5 & 5 & 0.68 & 0.67 \\
\hline
\end{tabular}

Fig. 4 PTC-209 reduces the effect of major myeloma growth factors and stromal support as well as displays synergistic activity with pomalidomide and carfilzomib. a PTC-209 was found to impair the growth and survival-propagating effects of IGF-1 and IL-6 in a dose-dependent manner. b The anti-MM activity of PTC-209 was upheld in the presence of BM stromal cells and promoted the activity of pomalidomide and carfilzomib. ${ }^{* * *} P<0.001$, ${ }^{* *} P<0.01$ and ${ }^{*} P<0.05$ vS PBS control; ${ }^{\# \#} P<0.001,{ }^{\# \#} P<0.01$ and ${ }^{\#} P<0.05$ vs IGF-1 control; ${ }^{++} P<0.001,{ }^{++} P<0.01$ and ${ }^{+} P<0.05$ vs IL-6 control. c Additive/synergistic activity of drug combinations was confirmed by concurrent treatment of MM cell lines with PTC-209 and either pomalidomide or carfilzomib for $96 \mathrm{~h}$ at varying concentrations. Graphs for MM.1S and U266 are representative for the panel of HMCLs analysed. Combination index (Cl) values were determined with CompuSyn. Cl values $<0.8,0.8-1.2$, or $>1.2$ indicate synergistic, additive or antagonistic drug activities, respectively

respectively) of tubes formed by human umbilical vein endothelial cells (HUVECs) after a 19-h incubation period (Fig. 5c).

As BMI-1 is known for its close interaction with the Wnt signalling pathway, we speculated that PTC-209 might affect osteoblast formation as well. We indeed observed a significant negative impact of PTC-209 on osteogenesis, evidenced by decreased alkaline phosphatase (ALP) activity $(68 \pm 4 \%$ reduction with PTC209 at
$1 \mu \mathrm{M}, P<0.001)$ and matrix mineralization in a dosedependent manner (Fig. 6a). The reduction in osteoblast formation was accompanied by a significant increase in Dickkopf-1 (DKK1) expression at day 7 of osteogenesis (1.5 \pm 0.1 -fold increase at $0.1 \mu \mathrm{M}$ PTC-209, $P<0.001)$ (Fig. 6b). We therefore investigated whether concurrent blockade of DKK1 with a neutralizing antibody could overcome the inhibitory effects on osteoblast formation. Bi-weekly treatment with anti-DKK1 antibody significantly 
A
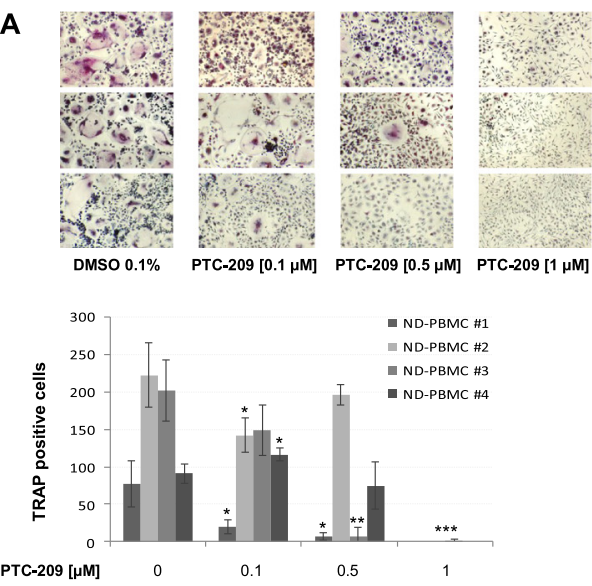

B

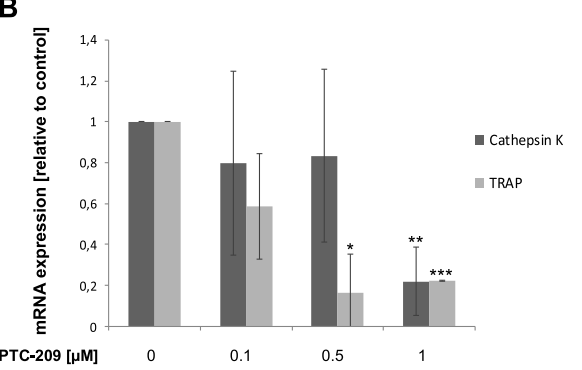

C
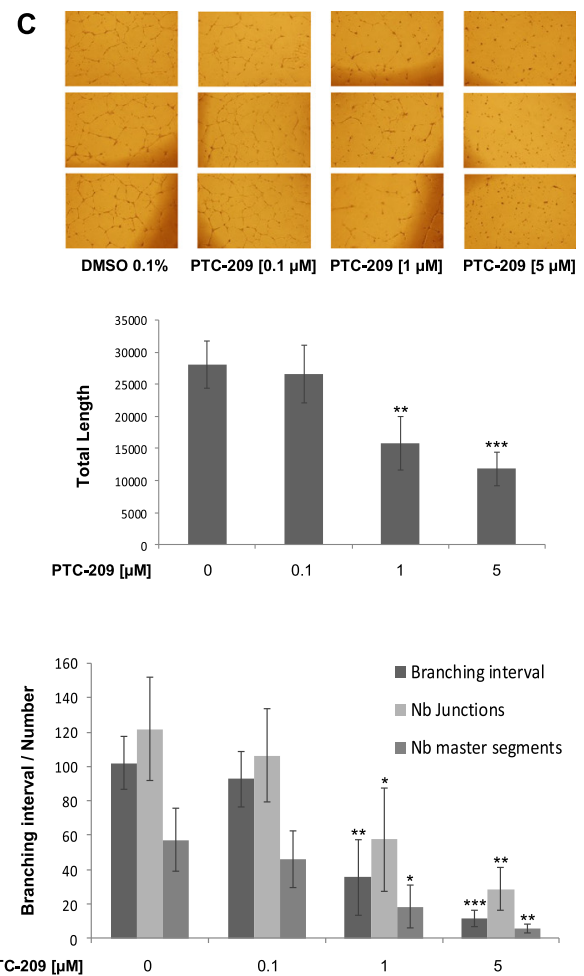

Fig. 5 PTC-209 impairs in vitro osteoclast and tube formation. a PTC-209 significantly inhibited osteoclast formation in a dose-dependent manner verified by reduced numbers of multinucleated TRAP-positive cells at day 14 of differentiation. $\mathbf{b}$ The inhibitory impact on osteoclast formation was confirmed by decreased expression of cathepsin K and TRAP. c Tube formation was inhibited by PTC-209 in a dose-dependent manner. Analysis with the Angiogenesis Analyzer for ImageJ demonstrated a significant impact of PTC-209 on the total length, the number of junctions and master segments as well as the branching interval (defined as total segments length/number of branches) during the tube formation process. Images are representative for three independent experiments. ${ }^{* *} P<0.001,{ }^{* *} P<0.01$ and ${ }^{*} P<0.05$ vs DMSO control

increased ALP activity in the presence of PTC-209 at $1 \mu \mathrm{M}(43 \pm 6$ vs $21 \pm 12 \%$ decrease in ALP activity, $P=$ 0.02 ), suggesting that the osteoblast inhibitory properties of PTC-209 might be, at least in part, mediated by DKK1 (Fig. 6c).

\section{Discussion}

In spite of the recent advances in the treatment of MM, the recurrence of myeloma after response to existing therapies is a major drawback on the way to cure. The identification of novel therapy targets and subsequent implementation of new anti-myeloma therapeutics is therefore urgently needed. Based on previous reports, inhibition of the polycomb complex protein BMI-1 might represent an attractive treatment approach for myeloma $[19,20]$, but therapeutic agents targeting BMI-1 are not available for clinical use so far. In the current study, we investigated the anti-MM activity of PTC-209, a novel small molecule inhibitor of BMI-1.

Our initial analysis of publically available GEP datasets confirmed the overexpression of BMI-1 in MM.
Overexpression of $B M I-1$ has been reported in various malignancies, including MM [18], and is typically associated with poor survival [9-13]. We likewise observed a significant elevated expression of BMI-1 in $\mathrm{MM}$ as well as in MGUS and SMM patients. Of note, $B M I-1$ expression was further elevated in relapsed TT3, but not TT2 patients. This suggests that the use of distinct treatment strategies such as the addition of bortezomib in TT3 specifically impacts BMI-1 levels. According to this assumption, shRNA-mediated silencing of BMI-1 was shown to sensitize MM cells to bortezomib [20]. Our observation of increased BMI-1 expression in relapsed TT3 patients suggests that further BMI-1 upregulation might confer a more aggressive phenotype during the progression of MM as it was shown in the progression of several other tumour entities [9, 12, 24-28]. This is also evidenced by an association of high BMI-1 expression with worse overall survival in relapsed and/or refractory patients treated with bortezomib or dexamethasone (Fig. 1b) [29]. These results confirmed BMI-1 overexpression in all stages of MM, from the onset of the 

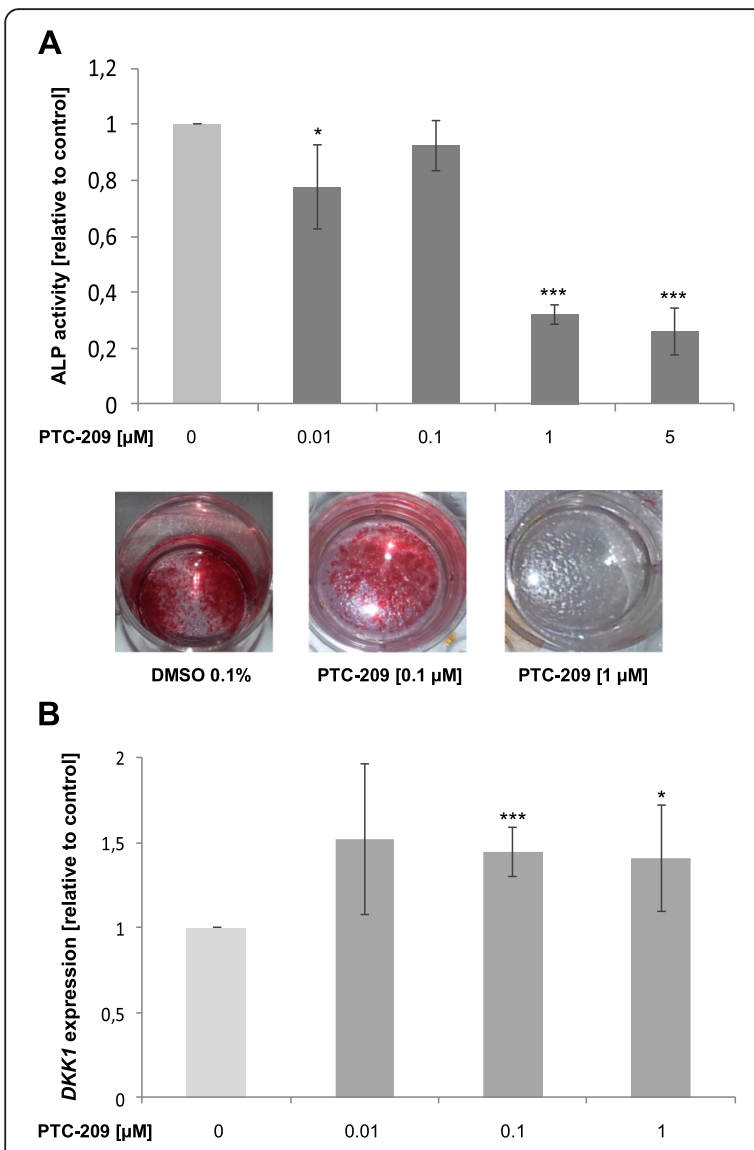

C

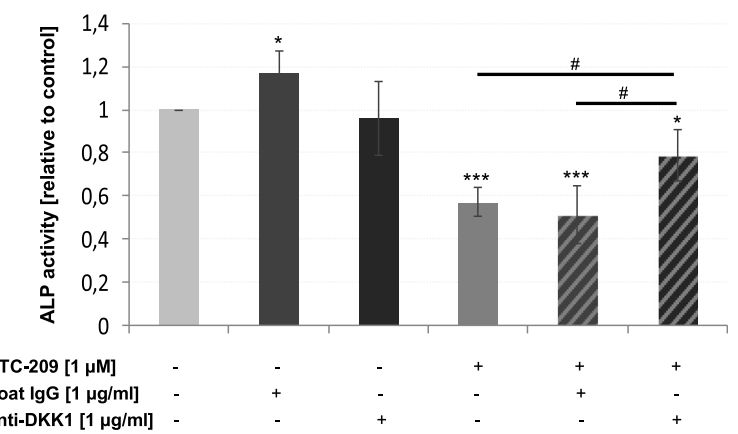

Fig. 6 PTC-209 inhibits osteogenesis via upregulation of DKK1. a PTC209 significantly inhibited osteoblast formation in a dose-dependent manner verified by reduced alkaline phosphatase activity and matrix mineralization at days 14 and 21 of differentiation, respectively. Images are representative for three independent experiments. $\mathbf{b}$ Treatment with PTC-209 increased DKK1 expression in developing osteoblasts at day 14 of osteogenesis. c The inhibitory effect of PTC-209 on osteoblast activity was partially overcome by concurrent anti-DKK1 antibody treatment. ${ }^{* *} P<0.001,{ }^{* *} P<0.01$ and ${ }^{*} P<0.05$ vs DMSO control; ${ }^{P} P<0.05$

disease until progression in response to therapy, underlining its central role as an attractive drug target in MM.

PTC-209 demonstrated significant anti-myeloma activity in all HMCLs analysed. In line with the effect of shRNA-mediated silencing of BMI-1 [19], we observed a significant impact on the colony formation of myeloma cells, suggesting that targeting BMI-1 also affects the viability of tumour-propagating cells. Recent reports indicated that PTC-209 targets cancer-initiating cells in colorectal and biliary tract cancer. In particular, PTC209 impaired sphere formation in both entities as well as growth of aldehyde dehydrogenase-positive $\left(\mathrm{ALDH}^{+}\right)$ cells in certain biliary tract cancer cell lines [21,30]. Future studies therefore have to clarify whether BMI-1 inhibition specifically targets tumour-propagating cells in $\mathrm{MM}$ as well.

Similar to shRNA-mediated BMI-1 inhibition in breast and lung adenocarcinoma cells [31, 32], the growthinhibiting effect of PTC-209 was associated with deregulation of CCND1, MYC, CDKN1A and CDKN1B. These genes are known to be implicated in the proliferation of MM cells and their deregulation therefore likely explains the accumulation of cells in the G1 phase and the impaired entry into the $S$ and G2M phase of the cell cycle. Induction of apoptosis was accompanied by a rapid increase of NOXA expression and subsequent reduction of MCL-1 protein levels. Prior studies reported that silencing of BMI-1 in MM cells was linked to increased expression of either Bim or Bax. However, in these studies, upregulation of Bim and Bax reached significance $48 \mathrm{~h}$ post BMI-1 silencing $[19,20]$. In the current study, upregulation of NOXA (but not Bim or Bax) was already observed $5 \mathrm{~h}$ post treatment with PTC-209, suggesting that NOXA might be upstream of Bim and Bax in the initiation of apoptosis after impairing BMI-1. According to this assumption, upregulation of NOXA leads to increased binding of NOXA to MCL-1, thereby releasing Bim from MCL-1 which subsequently mediates Bax (and Bak)-dependent induction of apoptosis [33, 34]. Similar to our results, a time-dependent increase of NOXA prior to Bim protein levels was observed in chronic lymphatic leukemia cells in response to histone deacetylase inhibitors (HDACi). HDACi were shown to induce a rapid increase of NOXA mRNA levels, which subsequently triggers MCL-1 binding and induces apoptosis [35]. Moreover, BMI-1 was shown to mediate the survival of memory CD4 $\mathrm{T}$ cells as well as mantle cell lymphoma cells via direct binding to the NOXA gene locus and repression of NOXA mRNA expression through histone modifications [14, 36]. These findings suggest that early upregulation of NOXA might release and activate Bim and Bax to exert their apoptotic effects upon BMI-1 inhibition.

Importantly, the anti-MM activity of PTC-209 was upheld in the presence of major myeloma growth factors (IGF-1 and IL-6) as well as in co-culture with BMSCs. Moreover, we observed synergistic activity of PTC-209 with pomalidomide, carfilzomib and dexamethasone, suggesting that inhibition of BMI-1 might improve 
current treatment strategies. A similar observation was made when BMI-1-silenced myeloma cells were treated with bortezomib. Concurrent treatment enhanced the anti-proliferative and apoptotic activity of bortezomib via pronounced induction of p21 and Bax [20].

In addition to its direct anti-myeloma effect, we demonstrated that PTC-209 showed a significant impact on stromal compartments as well. Little is known about the role of BMI-1 in the fate of BM environmental cells. Low expression levels of BMI-1 were associated with senescence in endothelial cells of the human cornea [37]. Moreover, BMI-1 was shown to promote the angiogenic activity of glioma and hepatocellular carcinoma cells [38-40]. In the current study, PTC-209 significantly inhibited osteoclast and tube formation in vitro. Increased osteoclast activity and formation as well as induction of angiogenesis are prominent features of the myeloma microenvironment. The interaction of myeloma cells and these compartments is implicated in tumour growth, progression and drug resistance [41]. Interfering with these manifestations therefore impairs MM cell growth and survival. Treatment with PTC-209 might thus not only target MM via direct effects on tumour cells, but also by impairing the crosstalk between tumour and stromal cells.

BMSCs of BMI-1 ${ }^{-1-}$ mice were shown to undergo a shift from osteogenesis to adipogenesis. Moreover, BMI$1^{-/-}$mice displayed an osteopenic phenotype characterized by skeletal growth retardation, decreased osteoblast numbers and activity [42, 43]. We also observed reduced osteoblast activity and formation in the presence of PTC-209. Considering the negative regulation of osteoblast development by myeloma cells, blockade of BMI-1 could aggravate these effects probably leading to skeletal-related side effects. We therefore aimed to identify the underlying mechanism for the decreased osteoblast formation. As BMI-1 is known for its close interaction with the Wnt signalling pathway [31], a major signalling pathway in osteogenesis [44], we speculated that the osteoblast inhibition observed in our study might be related to this connection. We indeed revealed a significant induction of $D K K 1$ expression in developing osteoblasts during PTC-209 treatment and that blockade of DKK1 with a specific antibody, at least in part, reversed the suppressive effect of PTC-209 on osteoblast activity. This suggests that combination therapy with anti-DKK1 antibodies might overcome the osteoblast suppressive effects of BMI-1 inhibition. In line with our results, silencing of BMI-1 in breast cancer cells was shown to impair Wnt signalling via downregulation of Wnt ligands (e.g. Wnt3a) and upregulation of Wnt inhibitors including DKK1. BMI-1 knockout was shown to upregulate DKK1 and to target cancer cells via subsequent downregulation of MYC and CCND1 [31].
Interestingly, short-term treatment $(5 \mathrm{~h})$ with PTC-209 was found to induce $D K K 1$ expression in myeloma cells as well (up to $5.0 \pm 1.9$-fold increase, $P<0.05$ ) (data not shown). This assumes that targeting Wnt signalling via BMI-1 blockade might also target myeloma cells. In line with this, inhibition of the Wnt signalling pathway was recently shown to affect the survival of mantle cell lymphomainitiating cells [45]. Considering the proposed roles of Wnt signalling in disease progression and therapy resistance [46-48], BMI-1 inhibition could significantly improveme existing therapies by overcoming drug resistance.

Numerous small molecule inhibitors are currently in clinical development to improve the treatment opportunities for MM patients. These include Bruton's tyrosine kinase [49], mitogen-activated protein kinase (MAPK) signalling cascade [50], phosphoinositol-3 kinase/AKT [51] and Bcl-2 family inhibitors [52] among others. Future studies have to clarify which of these agents provide the most potent anti-tumour activity, define predictive markers for an individualized treatment approach and examine the additive value in combination with standard regimens. Targeting of BMI-1 represents a promising novel therapeutic strategy among these evolving arsenals of specific inhibitors due to its universal expression pattern in MM and its impact on the myeloma microenvironment. Further studies evaluating the role of BMI-1 inhibition in myeloma and the applicability of more selective inhibitors (e.g. PTC596) in vitro and in vivo are therefore warranted.

\section{Conclusions}

We confirmed overexpression of BMI-1 in MM highlighting its role as an attractive drug target. In line with this, PTC-209 demonstrates potent anti-MM activity by targeting central myeloma survival genes (e.g. MYC, MCL-1), shows synergistic activity with pomalidomide, carfilzomib and dexamethasone, reduces the protective effect of soluble factors and BMSCs in certain cell lines, and impairs angiogenesis as well as osteoclast formation. Upregulation of $D K K 1$ suggests that the osteoblast suppressive effect of PTC-209 might be overcome by concurrent antibody treatment. Our data reveal therapeutic targeting of BMI-1 by PTC-209 as a promising novel therapeutic intervention for MM. Further studies examining the anti-myeloma activity of PTC-209 and more advanced BMI-1 inhibitors (e.g. PTC596) are therefore warranted.

\section{Methods}

\section{Reagents}

PTC-209, pomalidomide and carfilzomib were obtained from SelleckChem, dissolved in DMSO and stored at $-80{ }^{\circ} \mathrm{C}$. Dexamethasone was obtained from SigmaAldrich, dissolved in PBS and stored at $-20{ }^{\circ} \mathrm{C}$. Recombinant human IGF-1, IL-6, receptor activator of nuclear 
factor-kappa B ligand (RANKL) and macrophage colony-stimulating factor (M-CSF) were obtained from Peprotech, dissolved in PBS/BSA $0.1 \%$ and stored at $-20{ }^{\circ} \mathrm{C}$. Goat anti-human DKK1 neutralizing antibody and normal goat IgG were purchased from R\&D Systems, dissolved in PBS and stored at $-20{ }^{\circ} \mathrm{C}$.

\section{Cell lines and culture conditions}

Human multiple myeloma cell lines (HMCLs) U266, KMS-12-BM, OPM-2, NCI-H929, SK-MM-1 and RPMI8226 were obtained from the German Collection of Microorganisms and Cell Cultures (Braunschweig, Germany). MM.1S and MM.1R cells were kindly provided by Dr. Steven Rosen (Northwestern University, Chicago, IL). A human bone marrow mesenchymal stromal cell line immortalized by enforced expression of telomerase (BMSC TERT $^{+}$) was kindly provided by Dr. Dario Campana (St. Jude Children's Research Hospital, Memphis, TN). All cell lines were cultivated in RPMI1640 medium supplemented with $10 \%$ heat-inactivated fetal bovine serum, $2 \mathrm{mM}$ L-glutamine and $100 \mathrm{U} / \mathrm{ml}$ penicillin/streptomycin (Gibco). BMSC TERT ${ }^{+}$cells were supplemented with $1 \mu \mathrm{M}$ hydrocortisone (SigmaAldrich). For co-culture experiments, $1 \times 10^{5}$ BMSC TERT $^{+}$cells were seeded in 24-well plates and cultured overnight before $2 \times 10^{5} \mathrm{MM}$ cells were added per well for $72 \mathrm{~h}$.

\section{Cytotoxicity assay}

Viability was determined by using Cell Counting Kit 8 (Sigma-Aldrich) following the manufacturer's directions. In brief, HMCLs $\left(2 \times 10^{4}\right)$, BMSC TERT ${ }^{+}$cells $\left(1 \times 10^{4}\right)$ and PBMCs $\left(2.5 \times 10^{5}\right)$ were incubated in flat-bottomed 96-well plates (ThermoFisher Scientific) in the presence of PTC-209 $(0.01-10 \mu \mathrm{M})$ alone, or in combination with either pomalidomide $(1-5 \mu \mathrm{M})$ or carfilzomib (1-5 nM). Viability assessment in the presence of recombinant human IGF-1 $(10 \mathrm{ng} / \mathrm{ml})$ and IL-6 $(10 \mathrm{ng} / \mathrm{ml})$ was performed in serum-free Syn-H medium (ABCell-Bio). After 96 h, cells were incubated with WST-8, and absorbance was measured at $450 \mathrm{~nm}$ using a HTS 7000 Bio Assay Reader (Perkin Elmer).

\section{Colony formation assay}

HMCLs $\left(2 \times 10^{3}\right)$ either treated or untreated with PTC209 at $1 \mu \mathrm{M}$ were plated in duplicates in $1.1 \mathrm{ml}$ methylcellulose-based medium (MethoCult Classic, StemCell Technologies) per 6-well and incubated for 14 days $\left(37^{\circ} \mathrm{C}, 5 \% \mathrm{CO}_{2}\right)$. At the end of the incubation period, the number of colonies consisting of $>40$ cells was scored using an inverted microscope with $\times 4, \times 10$ and $\times 20$ planar objectives.

\section{Flow cytometry}

Induction of apoptosis was determined by Annexin V/7AAD staining (BD Biosciences). HMCLs were seeded in the presence or absence of $\mathrm{BMSC}^{\mathrm{TERT}}{ }^{+}$cells and treated with $0.1 \%$ DMSO (control), PTC-209 $(1 \mu \mathrm{M})$, pomalidomide $(1 \mu \mathrm{M})$ and/or carfilzomib $(5 \mathrm{nM})$ for $72 \mathrm{~h}$. Cells were incubated with Annexin V and 7-AAD for $15 \mathrm{~min}$ in the dark before performing analysis.

Cell cycle analysis was performed after treatment of HMCLs with PTC-209 $(1 \mu \mathrm{M})$ for $24 \mathrm{~h}$ using the FxCycle ${ }^{\mathrm{Tw}}$ $\mathrm{PI} / \mathrm{RNase}$ Staining solution (ThermoFisher Scientific) following the manufacturer's instructions.

Intracellular staining of BMI-1 and MCL-1 was performed using the BD Transcription Factor Buffer Set (BD Biosciences) according to the manual. After fixation and permeabilization, cells were incubated with a mouse anti-human MCL-1 antibody (ab197529, Abcam), mouse anti-human BMI-1 antibody (562528, BD Biosciences) or the corresponding isotype controls for $40 \mathrm{~min}$ at $4{ }^{\circ} \mathrm{C}$. Thereafter, cells were washed and analysed. All analyses were performed on a FACScan (BD Biosciences).

\section{Quantitative RT-PCR}

Total RNA was isolated using RNeasy kit (Qiagen), and cDNA synthesis was performed with M-MuLV reverse transcriptase (New England Biolabs). CDKN1A, CDKN1B, $M Y C, C C N D 1, N O X A$, TRAP, cathepsin $\mathrm{K}$ and DKK1 expression levels were analysed by quantitative PCR (qPCR) using TaqMan Universal PCR Master Mix and pre-designed TaqMan gene expression assays (Applied Biosystems). RPLPO served as endogenous control. Reactions were carried out in $25 \mu \mathrm{l}$ volumes and run on the ABI Prism 7300 platform (Applied Biosystems). All samples were run at least in duplicates.

\section{PARP ELISA}

Levels of cleaved PARP were analysed by using a commercially available ELISA kit (Invitrogen) following the manual. In brief, cell lysates were incubated with cleaved PARP detection antibody for $3 \mathrm{~h}$ at room temperature on an orbital shaker. Subsequently, wells were washed and incubated with anti-rabbit IgG HRP for $30 \mathrm{~min}$ at room temperature. After an additional wash step, $100 \mu \mathrm{l}$ stabilized chromogen was added per well, the plate was incubated for $30 \mathrm{~min}$ at room temperature in the dark and finally mixed with $100 \mu \mathrm{l}$ stop solution per well. Absorbance was measured at $450 \mathrm{~nm}$, and levels of cleaved PARP were determined in relation to a standard curve.

\section{Osteogenic differentiation}

BMSCs were seeded at a density of 25,000 per square centimetre and grown to $70-80 \%$ confluence. Osteoblast differentiation was initiated by changing the medium to alpha-MEM supplemented with $15 \%$ FBS, 2 mM L- 
glutamine, $100 \mathrm{U} / \mathrm{ml}$ penicillin, $100 \mu \mathrm{g} / \mathrm{ml}$ streptomycin, $10 \mathrm{nM}$ dexamethasone, $50 \mu \mathrm{g} / \mathrm{ml}$ ascorbic acid and $5 \mathrm{mM}$ $\beta$-glycerophosphate (Sigma-Aldrich). Osteogenic medium was changed every 3-4 days. PTC-209, normal goat IgG $(1 \mu \mathrm{g} / \mathrm{ml})$ and/or anti-DKK1 neutralizing antibody $(1 \mu \mathrm{g} /$ $\mathrm{ml}$ ) were added with every medium change. Cells treated with $0.1 \%$ DMSO served as control. Osteoblast formation was assessed by alkaline phosphatase activity assay and alizarin red S staining as described previously [53, 54].

\section{Osteoclast differentiation}

Human PBMCs were obtained from voluntary healthy donors and cultured $\left(2.5 \times 10^{6} / \mathrm{ml}\right)$ overnight in 24 -well plates to remove non-adherent cells. Subsequently, osteoclast differentiation was initiated by changing the medium to alpha-MEM supplemented with $10 \% \mathrm{FBS}, 2 \mathrm{mM} \mathrm{L}$-glutamine, $100 \mathrm{U} / \mathrm{ml}$ penicillin, $100 \mu \mathrm{g} / \mathrm{ml}$ streptomycin, $50 \mathrm{ng} / \mathrm{ml}$ RANKL and $25 \mathrm{ng} / \mathrm{ml} \mathrm{M}$-CSF in the presence or absence of PTC-209. Medium was changed every 3-4 days. At day 14, cultures were fixed and stained using the Acid Phosphatase Leukocyte Kit (Sigma-Aldrich) according to the manufacturer's instructions. Cells were evaluated using an inverted microscope and multinucleated TRAP-positive cells ( $>3$ nuclei) were scored as mature osteoclasts.

\section{Tube formation}

Tube formation was assessed following the manual of the Angiogenesis Starter Kit (Gibco). Briefly, human umbilical vein endothelial cells (HUVECs) were seeded in LVESsupplemented medium 200 at a density of $2.5 \times 10^{3}$ cells per square centimetre. For in vitro tube formation, $80 \%$ confluent cultures were harvested, and HUVECs $(50,000$ per 24-well plate) were plated on Geltrex ${ }^{\circ}$ Matrix precoated wells in the presence or absence of PTC-209. Tube networks were documented $19 \mathrm{~h}$ post-seeding by using an inverted microscope. Analysis was performed using the Angiogenesis Analyzer for Image J (http://image.bio.methods.free.fr/ImageJ/?Angiogenesis-Analyzer-forImageJ.html).

\section{Gene expression analysis}

For the illustration of $B M I-1$ expression in $\mathrm{CD} 138^{+}$purified bone marrow samples as well as for the assessment of overall survival in different MM patients, following datasets from the Gene Expression Omnibus (GEO) were selected: GSE2658 (consisting of 559 samples from newly diagnosed MM patients treated within the TT2 and TT3 protocol), GSE5900 (22 healthy controls, 44 MGUS patients and 12 SMM patients), GSE6477 (15 healthy controls, 22 MGUS patients, 24 SMM patients, 73 newly diagnosed and 28 relapsed MM patients), GSE31161 (346 TT2 baseline and 127 TT2 relapse samples as well as 433 TT3 baseline and 29 TT3 relapse samples) and GSE9782 (264 relapsed and/or refractory MM patients treated with bortezomib or dexamethasone). The GSE9782 dataset was established by Mulligan et al. (2007) and contains data from 156 patients treated within the APEX phase 3 trial, 57 patients treated within a companion study to receive bortezomib after progressive disease with dexamethasone, 44 patients treated within the SUMMIT phase 2 trial and 7 patients treated within the CREST phase 2 trial [29].

Expression and clinical data were downloaded into $\mathrm{R}$ using the Bioconductor GEOquery package. For GSE6477, GSE5900 and GSE31161, raw CEL files were downloaded from GEO and analyses were performed on gcrmanormalized samples in R. In case of GSE2658, corresponding raw CEL files were downloaded from GEO study GSE24080 in order to perform a gcrma-normalization on the raw data using the 'affy' package from Bioconductor (since raw CEL files are not provided in the GSE2658 dataset). For GSE9782, mas5 expression sets were retrieved for analysis using the GEOquery package, since raw CEL files are not provided for this study.

\section{Statistical analysis}

Survival analysis was performed in R using the 'survival' package. In order to split the patients into two groups with different survival probabilities exhibiting higher or lower $B M I-1$ expression, the maximally selected rank statistics, implemented in the maxstat $\mathrm{R}$ package, was applied to the $B M I-1$ expression data. The statistical significance of differences in overall survival between the two groups was calculated by the log-rank test, and survival curves were plotted using the Kaplan-Meier method. For the analysis of in vitro experiments, two-tailed unpaired $t$ test was performed using Prism 5 (GraphPad Software Inc., La Jolla, CA, USA). $P$ values $<0.05$ were considered to be statistically significant. Graphs represent the mean \pm standard deviation of at least three independent experiments performed in triplicates. Synergistic, additive or antagonistic drug activities of combination treatments were determined by using CompuSyn software.

\section{Additional file}

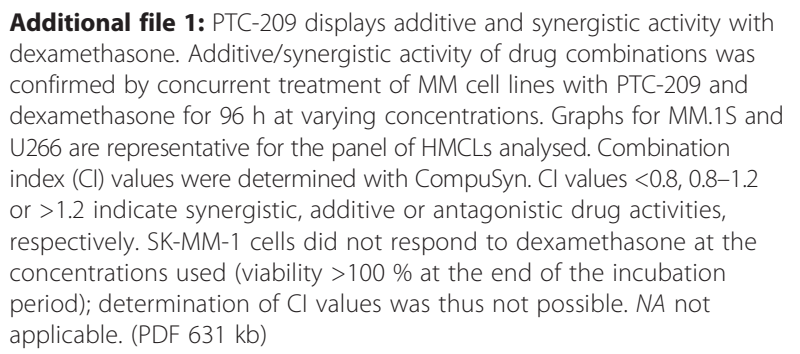

Additional file 1: PTC-209 displays additive and synergistic activity with dexamethasone. Additive/synergistic activity of drug combinations was confirmed by concurrent treatment of MM cell lines with PTC-209 and dexamethasone for $96 \mathrm{~h}$ at varying concentrations. Graphs for MM.1S and U266 are representative for the panel of HMCLs analysed. Combination index $(\mathrm{Cl})$ values were determined with CompuSyn. $\mathrm{Cl}$ values $<0.8,0.8-1.2$ or $>1.2$ indicate synergistic, additive or antagonistic drug activities, respectively. SK-MM-1 cells did not respond to dexamethasone at the concentrations used (viability $>100 \%$ at the end of the incubation period); determination of $\mathrm{Cl}$ values was thus not possible. NA not applicable. (PDF 631 kb)

\section{Abbreviations}

ALDH: aldehyde dehydrogenase; ALP: alkaline phosphatase; Bax: BCL2associated X protein; Bim: BCL2-like 11; BM: bone marrow; BMI-1: polycomb complex protein BMI-1; BMSC: bone marrow stromal cell; CCND1: cyclin D1; 
CDKN1A: cyclin-dependent kinase inhibitor 1A; CDKN1B: cyclin-dependent kinase inhibitor 1B; Cl: combination index; DKK1: Dickkopf-1; GEP: gene expression profiling; HDACi: histone deacetylase inhibitor; HMCL: human myeloma cell line; HUVEC: human umbilical vein endothelial cell; IGF-1: insulin-like growth factor 1; IL-6: interleukin 6; MCL-1: myeloid cell leukemia 1; M-CSF: macrophage colony-stimulating factor; MGUS: monoclonal gammopathy of undetermined significance; MM: multiple myeloma; MMSET: multiple myeloma SET domain; OS: overall survival; MYC: v-myc avian myelocytomatosis viral oncogene homolog; PARP: poly(ADP-ribose) polymerase; PBMC: peripheral blood mononuclear cell; PC: plasma cell; PRC1: polycomb repressive complex 1; RANKL: receptor activator of NF-kappa B ligand; SMM: smouldering multiple myeloma; TRAP: tartrate-resistant acid phosphatase; TT: total therapy.

\section{Competing interests}

The authors declare that they have no competing interests.

\section{Authors' contributions}

$A B$ and $H L$ designed the research. $A B$ performed the experiments and analysed the data. KS and WS performed the analysis of the GEP datasets. $A B, N Z$ and $H L$ wrote the paper. All authors reviewed and approved the final version of the manuscript.

\section{Acknowledgements}

This study was supported by the Austrian Forum against Cancer. The authors would like to thank Lisa Holzer and Waltraud Scherbler for excellent technical assistance.

\section{Author details}

'Wilhelminen Cancer Research Institute, Department of Medicine I, Wilhelminenspital, Montleartstraße 37, 1160 Vienna, Austria. ${ }^{2}$ Center for Medical Statistics, Informatics and Intelligent Systems, Medical University of Vienna, Vienna, Austria.

Received: 23 December 2015 Accepted: 23 February 2016 Published online: 02 March 2016

\section{References}

1. Palumbo A, Anderson K. Multiple myeloma. N Engl J Med. 2011;364:1046-60.

2. Kumar SK, Dispenzieri A, Lacy MQ, Gertz MA, Buadi FK, Pandey S, et al. Continued improvement in survival in multiple myeloma: changes in early mortality and outcomes in older patients. Leukemia. 2014;28:1122-8.

3. Cao L, Bombard J, Cintron K, Sheedy J, Weetall ML, Davis TW. BMI1 as a novel target for drug discovery in cancer. J Cell Biochem. 2011;112:2729-41.

4. Haupt $Y$, Alexander WS, Barri G, Klinken SP, Adams JM. Novel zinc finger gene implicated as myc collaborator by retrovirally accelerated lymphomagenesis in E mu-myc transgenic mice. Cell. 1991;65:753-63.

5. Haupt Y, Bath ML, Harris AW, Adams JM. bmi-1 transgene induces lymphomas and collaborates with myc in tumorigenesis. Oncogene. 1993;8:3161-4.

6. Brunk BP, Martin EC, Adler PN. Drosophila genes posterior sex combs and suppressor two of zeste encode proteins with homology to the murine bmi-1 oncogene. Nature. 1991;353:351-3.

7. Hernández-Muñoz I, Taghavi P, Kuijl C, Neefjes J, van Lohuizen M. Association of BMI1 with polycomb bodies is dynamic and requires PRC2/ EZH2 and the maintenance DNA methyltransferase DNMT1. Mol Cell Biol. 2005;25:11047-58.

8. Cao R, Tsukada Y-I, Zhang Y. Role of Bmi-1 and Ring1A in H2A ubiquitylation and Hox gene silencing. Mol Cell. 2005;20:845-54.

9. Song L-B, Zeng M-S, Liao W-T, Zhang L, Mo H-Y, Liu W-L, et al. Bmi-1 is a novel molecular marker of nasopharyngeal carcinoma progression and immortalizes primary human nasopharyngeal epithelial cells. Cancer Res. 2006;66:6225-32

10. Wang H, Pan K, Zhang H, Weng D, Zhou J, Li J, et al. Increased polycombgroup oncogene Bmi-1 expression correlates with poor prognosis in hepatocellular carcinoma. J Cancer Res Clin Oncol. 2008;134:535-41.

11. Tong Y-Q, Liu B, Zheng H-Y, He Y-J, Gu J, Li F, et al. Overexpression of BMI-1 is associated with poor prognosis in cervical cancer. Asia Pac J Clin Oncol. 2012;8:e55-62

12. Mihara K, Chowdhury M, Nakaju N, Hidani S, Ihara A, Hyodo H, et al. Bmi-1 is useful as a novel molecular marker for predicting progression of myelodysplastic syndrome and patient prognosis. Blood. 2006;107:305-8.
13. Chowdhury M, Mihara K, Yasunaga S, Ohtaki M, Takihara Y, Kimura A. Expression of Polycomb-group (PCG) protein BMl-1 predicts prognosis in patients with acute myeloid leukemia. Leukemia. 2007;21:1116-22.

14. Teshima $K$, Nara M, Watanabe A, Ito M, Ikeda S, Hatano Y, et al. Dysregulation of BMI1 and microRNA-16 collaborate to enhance an anti-apoptotic potential in the side population of refractory mantle cell lymphoma. Oncogene. 2014;33:2191-203.

15. Yuan J, Takeuchi M, Negishi M, Oguro H, Ichikawa H, Iwama A. Bmi1 is essential for leukemic reprogramming of myeloid progenitor cells. Leukemia. 2011;25: 1335-43.

16. Yadirgi G, Leinster V, Acquati S, Bhagat $\mathrm{H}$, Shakhova O, Marino S. Conditional activation of Bmi1 expression regulates self-renewal, apoptosis, and differentiation of neural stem/progenitor cells in vitro and in vivo. Stem Cells. 2011;29:700-12.

17. Chiba T, Miyagi S, Saraya A, Aoki R, Seki A, Morita Y, et al. The polycomb gene product BMI1 contributes to the maintenance of tumor-initiating side population cells in hepatocellular carcinoma. Cancer Res. 2008;68:7742-9.

18. De Vos J, Thykjaer T, Tarte K, Ensslen M, Raynaud P, Requirand G, et al. Comparison of gene expression profiling between malignant and normal plasma cells with oligonucleotide arrays. Oncogene. 2002;21:6848-57.

19. Jagani Z, Wiederschain D, Loo A, He D, Mosher R, Fordjour P, et al. The polycomb group protein Bmi-1 is essential for the growth of multiple myeloma cells. Cancer Res. 2010;70:5528-38.

20. Wu S-Q, Xu Z-Z, Niu W-Y, Huang H-B, Zhan R. ShRNA-mediated Bmi-1 silencing sensitizes multiple myeloma cells to bortezomib. Int J Mol Med. 2014;34:616-23.

21. Kreso A, van Galen P, Pedley NM, Lima-Fernandes E, Frelin C, Davis T, et al. Self-renewal as a therapeutic target in human colorectal cancer. Nat Med. 2014;20:29-36.

22. Nishida Y, Maeda A, Chachad D, Ishizawa J, Yi Hua Q, Kornblau SM, et al. Preclinical activity of the novel BMI-1 inhibitor PTC-209 in acute myeloid leukemia: implications for leukemia therapy. Cancer Sci. 2015;106:1705-13.

23. Mourgues L, Imbert V, Nebout M, Colosetti P, Neffati Z, Lagadec P, et al. The BMI1 polycomb protein represses cyclin G2-induced autophagy to support proliferation in chronic myeloid leukemia cells. Leukemia. 2015;29: 1993-2002.

24. Kang MK, Kim RH, Kim SJ, Yip FK, Shin K-H, Dimri GP, et al. Elevated Bmi-1 expression is associated with dysplastic cell transformation during oral carcinogenesis and is required for cancer cell replication and survival. $\mathrm{Br} \mathrm{J}$ Cancer. 2007;96:126-33.

25. Guo B-H, Feng Y, Zhang R, Xu L-H, Li M-Z, Kung H-F, et al. Bmi-1 promotes invasion and metastasis, and its elevated expression is correlated with an advanced stage of breast cancer. Mol Cancer. 2011;10:10.

26. Wu Z, Min L, Chen D, Hao D, Duan Y, Qiu G, et al. Overexpression of BMl-1 promotes cell growth and resistance to cisplatin treatment in osteosarcoma. PLoS One. 2011;6:e14648.

27. Jiang L, Wu J, Yang Y, Liu L, Song L, Li J, et al. Bmi-1 promotes the aggressiveness of glioma via activating the NF-kappaB/MMP-9 signaling pathway. BMC Cancer. 2012;12:406.

28. Yang D-D, Cui B-B, Sun L, Zheng H, Huang Q, Tong J-X, et al. The co-expression of USP22 and BMI-1 may promote cancer progression and predict therapy failure in gastric carcinoma. Cell Biochem Biophys. 2011;61:703-10

29. Mulligan G, Mitsiades C, Bryant B, Zhan F, Chng WJ, Roels S, et al. Gene expression profiling and correlation with outcome in clinical trials of the proteasome inhibitor bortezomib. Blood. 2007;109:3177-88.

30. Mayr C, Wagner A, Loeffelberger M, Bruckner D, Jakab M, Berr F, et al. The BMI1 inhibitor PTC-209 is a potential compound to halt cellular growth in biliary tract cancer cells. Oncotarget. 2015;7:745-58.

31. Cho J-H, Dimri M, Dimri GP. A positive feedback loop regulates the expression of polycomb group protein BMI1 via WNT signaling pathway. J Biol Chem. 2013:288:3406-18,

32. Zheng $X$, Wang Y, Liu B, Liu C, Liu D, Zhu J, et al. Bmi-1-shRNA inhibits the proliferation of lung adenocarcinoma cells by blocking the G1/S phase through decreasing cyclin D1 and increasing p21/p27 levels. Nucleic Acid Ther. 2014;24:210-6.

33. Han J, Goldstein LA, Hou W, Rabinowich H. Functional linkage between NOXA and Bim in mitochondrial apoptotic events. J Biol Chem. 2007;282: 16223-31.

34. Aikawa T, Shinzawa K, Tanaka N, Tsujimoto Y. Noxa is necessary for hydrogen peroxide-induced caspase-dependent cell death. FEBS Lett. 2010; 584:681-8. 
35. Inoue S, Riley J, Gant TW, Dyer MJS, Cohen GM. Apoptosis induced by histone deacetylase inhibitors in leukemic cells is mediated by Bim and Noxa. Leukemia. 2007;21:1773-82.

36. Yamashita M, Kuwahara M, Suzuki A, Hirahara K, Shinnaksu R, Hosokawa H, et al. Bmi1 regulates memory CD4 T cell survival via repression of the Noxa gene. J Exp Med. 2008;205:1109-20.

37. Wang $Y$, Zang $X$, Wang $Y$, Chen P. High expression of p16INK4a and low expression of Bmi1 are associated with endothelial cellular senescence in the human cornea. Mol Vis. 2012;18:803-15.

38. Jiang L, Song L, Wu J, Yang Y, Zhu X, Hu B, et al. Bmi-1 promotes glioma angiogenesis by activating NF-KB signaling. PLoS One. 2013;8:e55527.

39. Xu C-R, Lee S, Ho C, Bommi P, Huang S-A, Cheung ST, et al. Bmil functions as an oncogene independent of Ink4A/Arf repression in hepatic carcinogenesis. Mol Cancer Res. 2009;7:1937-45.

40. Chen F, Chen L, He H, Huang W, Zhang R, Li P. Meng Y, Jiang X. Upregulation of microRNA-16 in glioblastoma inhibits the function of endothelial cells and tumor angiogenesis by targeting Bmi-1. Anticancer Agents Med Chem. 2015. Epub ahead of print.

41. Kawano Y, Moschetta M, Manier S, Glavey S, Görgün GT, Roccaro AM, et al. Targeting the bone marrow microenvironment in multiple myeloma. Immunol Rev. 2015;263:160-72.

42. Zhang H-W, Ding J, Jin J-L, Guo J, Liu J-N, Karaplis A, et al. Defects in mesenchymal stem cell self-renewal and cell fate determination lead to an osteopenic phenotype in Bmi-1 null mice. J Bone Miner Res. 2010;25:640-52.

43. Xie C, Jin J, Lv X, Tao J, Wang R, Miao D. Anti-aging effect of transplanted amniotic membrane mesenchymal stem cells in a premature aging model of Bmi-1 deficiency. Sci Rep. 2015;5:13975.

44. Lin GL, Hankenson KD. Integration of BMP, Wnt, and notch signaling pathways in osteoblast differentiation. J Cell Biochem. 2011;112:3491-501.

45. Mathur R, Sehgal L, Braun FK, Berkova Z, Romaguerra J, Wang M, et al. Targeting Wnt pathway in mantle cell lymphoma-initiating cells. J Hematol Oncol. 2015;8:63.

46. Takada K, Zhu D, Bird GH, Sukhdeo K, Zhao J-J, Mani M, et al. Targeted disruption of the $B C L 9 / \beta$-catenin complex inhibits oncogenic Wnt signaling. Sci Transl Med. 2012;4:148ra117.

47. Yao H, Ashihara E, Strovel JW, Nakagawa Y, Kuroda J, Nagao R, et al. AV-65, a novel Wnt/ $\beta$-catenin signal inhibitor, successfully suppresses progression of multiple myeloma in a mouse model. Blood Cancer J. 2011;1:e43.

48. Bjorklund CC, Ma W, Wang Z-Q, Davis RE, Kuhn DJ, Kornblau SM, et al. Evidence of a role for activation of Wnt/beta-catenin signaling in the resistance of plasma cells to lenalidomide. J Biol Chem. 2011;286:11009-20.

49. Tai YT, Chang BY, Kong S-Y, Fulciniti M, Yang G, Calle Y, et al. Bruton tyrosine kinase inhibition is a novel therapeutic strategy targeting tumor in the bone marrow microenvironment in multiple myeloma. Blood. 2012; 120:1877-87.

50. Kim K, Kong S-Y, Fulciniti M, Li X, Song W, Nahar S, et al. Blockade of the MEK ERK signalling cascade by AS703026, a novel selective MEK1/2 inhibitor, induces pleiotropic anti-myeloma activity in vitro and in vivo. $\mathrm{Br} J$ Haematol. 2010;149:537-49.

51. Spencer A, Yoon S-S, Harrison SJ, Morris SR, Smith DA, Brigandi RA, et al. The novel AKT inhibitor afuresertib shows favorable safety, pharmacokinetics, and clinical activity in multiple myeloma. Blood. 2014;124: 2190-5.

52. Cang S, Iragavarapu C, Savooji J, Song Y, Liu D. ABT-199 (venetoclax) and BCL-2 inhibitors in clinical development. J Hematol Oncol. 2015;8:129.

53. Bolomsky A, Schreder M, Meißner T, Hose D, Ludwig H, Pfeifer $S$, et al. Immunomodulatory drugs thalidomide and lenalidomide affect osteoblast differentiation of human bone marrow stromal cells in vitro. Exp Hematol. 2014;42:516-25.

54. Bolomsky A, Hose D, Schreder M, Seckinger A, Lipp S, Klein B, et al. Insulin like growth factor binding protein 7 (IGFBP7) expression is linked to poor prognosis but may protect from bone disease in multiple myeloma. J Hematol Oncol. 2015:8:10.

\section{Submit your next manuscript to BioMed Central and we will help you at every step:}

- We accept pre-submission inquiries

- Our selector tool helps you to find the most relevant journal

- We provide round the clock customer support

- Convenient online submission

- Thorough peer review

- Inclusion in PubMed and all major indexing services

- Maximum visibility for your research

Submit your manuscript at www.biomedcentral.com/submit
Biomed Central 